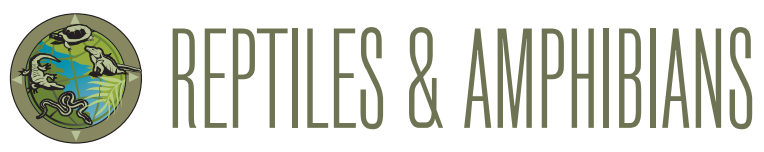

\title{
A Common Krait, Bungarus caeruleus (Schneider 1801), Preying on a Streaked Kulkri Snake, Oligodon taeniolatus (Jerdon 1853)
}

\author{
Sibasish Sahoo ${ }^{1}$ and Shantibhushan Sahoo ${ }^{2}$ \\ ${ }^{1}$ Wildlife Institute of India, Dehradun, Uttarakhand-248001, India (sibasish13@gmail.com) \\ ${ }^{2}$ Department of Wildlife \& Biodiversity Conservation, North Orissa University, Baripada, Odisha-757003, India
}

Common Kraits (Bungarus caeruleus) and Streaked Kukri

Snakes (Oligodon taeniolatus) are widely distributed throughout the Indian Subcontinent (Uetz et al. 2016). The diet of Common Kraits includes frogs, lizards, birds, rodents, and snakes (Whitaker and Captain 2004; Debata 2017; Pandey et al. 2018, 2020). Species of snakes known to be consumed by Common Kraits include the Banded Racer (Argyrogena fasciolata) (Mohalik et al. 2019) and Whitaker's Boa (Eryx whitakeri) (Chowdhury and Chaudhuri 2017). Herein we describe a Common Krait feeding on a Streaked Kukri snake in Odisha, India.

At 1529 h on 9 July 2019, we encountered an adult $B$. caeruleus (total length ca. $80 \mathrm{~cm}$ ) in a grassy area near human habitations and agricultural fields at Kaduadiha, Kendujhar District, Odisha, India $\left(21.35029^{\circ} \mathrm{N}, 85.76303^{\circ} \mathrm{E}\right.$; elev. 356 $\mathrm{m}$ asl), holding a Streaked Kukri Snake $(65 \mathrm{~cm})$ at midbody. After a minute, the krait moved a few meters, adjusted its grip on its prey, and ingested the kukri snake headfirst in the next four minutes (Fig. 1). Although Common Kraits are thought to be nocturnal (Whitaker and Captain 2004), this event occurred at mid-afternoon.

\section{Acknowledgements}

We are thankful to Bikash Kumar Sahoo and Badrinarayan Mahakud for their manpower assistance during field activities.

\section{Literature Cited}

Chowdhury, S. and A. Chaudhuri. 2017. Bungarus caeruleus (Common Krait). Diet. Herpetological Review 48: 856-857.

Debata, S. 2017. Bungarus caeruleus (Common Krait). Diet/scavenging. Herpetological Review 48: 857.

Mohalik, R.K., S.B. Sahu, A. Mirza, and N.B. Kar. 2018. Bungarus caeruleus (Common Krait). Coloration and diet. Herpetological Review 50: 150-151.

Pandey, D., P. Bhattarai, and R.C. Piya. 2018. Food spectrum of the common krait (Bungarus caeruleus): An implication for snakebite prevention and snake conservation. Toxicon 150: 330-331. DOI: 10.1016/j.toxicon.2018.06.048.

Pandey, D., P. Bhattarai, and R.C. Piya. 2020. Food spectrum of Common Kraits (Bungarus caeruleus): An implication for snakebite prevention and snake conservation. Journal of Herpetology 54: 87-96. https://doi.org.10.1670/18-054.

Uetz, P., J. Hošek, and J. Hallermann (eds.). 2016. The Reptile Database. <www. reptile-database.org>.

Whitaker, R. and A. Captain. 2004. Snakes of India. The Field Guide. Draco Books, Chennai, India.
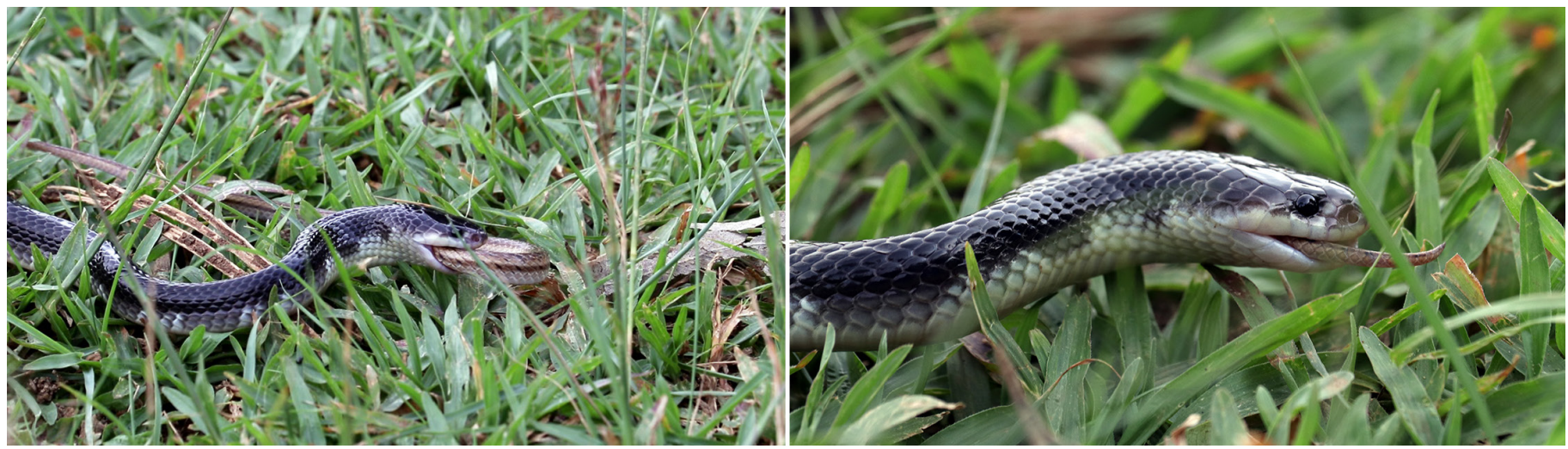

Fig. 1. An adult Common Krait (Bungarus caeruleus) ingesting a Streaked Kukri Snake (Oligodon taeniolatus). Photographs by Sibasish Sahoo. 